\title{
Ephrin-B1 regulates axon guidance by reverse signaling through a PDZ-dependent mechanism
}

\author{
Jeffrey O. Bush and Philippe Soriano ${ }^{1}$ \\ Program in Developmental Biology and Division of Basic Sciences, Fred Hutchinson Cancer Research Center, Seattle, \\ Washington 98109, USA; and Department of Developmental and Regenerative Biology, Mt. Sinai School of Medicine, \\ New York, New York 10029, USA
}

\begin{abstract}
Mutations in the ephrin-B1 gene result in craniofrontonasal syndrome (CFNS) in humans, a congenital disorder that includes a wide range of craniofacial, skeletal, and neurological malformations. In addition to the ability of ephrin-B1 to forward signal through its cognate EphB tyrosine kinase receptors, ephrin-B1 can also act as a receptor and transduce a reverse signal by either PDZ-dependent or phosphorylation-dependent mechanisms. To investigate how ephrin-B1 acts to influence development and congenital disease, we generated mice harboring a series of targeted point mutations in the ephrin-B1 gene that independently ablate specific reverse signaling pathways, while maintaining forward signaling capacity. We demonstrate that both PDZ and phosphorylationdependent reverse signaling by ephrin-B1 are dispensable for craniofacial and skeletal development, whereas PDZdependent reverse signaling by ephrin-B1 is critical for the formation of a major commissural axon tract, the corpus callosum. Ephrin-B1 is strongly expressed within axons of the corpus callosum, and reverse signaling acts autonomously in cortical axons to mediate an avoidance response to its signaling partner EphB2. These results demonstrate the importance of PDZ-dependent reverse signaling for a subset of Ephrin-B1 developmental roles in vivo.
\end{abstract}

[Keywords: Corpus callosum; craniofrontonasal syndrome; Ephrin; reverse signaling]

Supplemental material is available at http://www.genesdev.org.

Received March 31, 2009; revised version accepted May 12, 2009.

The capacity for bidirectional signaling is a hallmark of the Eph/ephrin signaling system: In addition to their ability to signal through cognate Eph tyrosine kinase receptors, ephrins can also transduce a reverse signal into the cell in which they are expressed (Davy and Soriano 2005). Bidirectional signaling can occur for both A- and B-type subfamilies, although the mechanisms by which ephrins accomplish this reverse signal differ. Ephrin-As are tethered to the membrane via a GPI linkage, whereas ephrin-Bs are transmembrane molecules and possess a conserved intracellular domain. Ephrin-B1, a member of the B-type subfamily, can bind EphB1-3, although genetic studies comparing phenotypes of mice harboring loss-of-function mutations in the receptors and ligands suggest that EphB2 and EphB3 are the principal receptors for ephrin-B1 in most developmental contexts (Orioli et al. 1996; Compagni et al. 2003; Blits-Huizinga et al. 2004). The capacity for bidirectional signaling was initially identified based on discordances between pheno-

${ }^{1}$ Corresponding author.

E-MAIL philippe.soriano@mssm.edu; FAX (212) 860-9279.

Article published online ahead of print. Article and publication date are online at http://www.genesdev.org/cgi/doi/10.1101/gad.1807209. types observed in complete loss-of-function mutations of EphB2 compared with mutations in which only the kinase domain of EphB2 was mutated, leaving the extracellular portion intact (Henkemeyer et al. 1996). Whereas EphB2 homozygous null mutant mice displayed defects in the axon pathfinding of the anterior commissure, EphB2 mutants lacking kinase activity did not display these defects, indicating that kinase activity was not required for EphB2s role in anterior commissure formation (Henkemeyer et al. 1996). Direct genetic evidence for reverse signaling has since been obtained by the analysis of mutations in B-type ephrins that abrogate reverse signaling while maintaining forward signaling capacity; however, the relative importance and mechanism of action of ephrin-B1 reverse signaling remain unknown (Yokoyama et al. 2001; Dravis et al. 2004; Makinen et al. 2005; Xu and Henkemeyer 2009).

Two molecular mechanisms by which a reverse signal may be transduced have been identified, both of which depend on the highly conserved intracellular portion of the ephrin-B molecule. First, a phosphorylation-dependent reverse signal can be initiated by the phosphorylation of multiple, conserved tyrosines on the intracellular 
domain of B-type ephrins, facilitating binding of the $\mathrm{SH} 2$ / SH3 domain adaptor protein Grb4 and subsequent cytoskeletal remodeling (Holland et al. 1996; Bruckner et al. 1997; Cowan and Henkemeyer 2001). Data indicating that ephrin-Bs can be phosphorylated by Src kinase, or by receptor tyrosine kinases such as PDGFR, FGFR, EGFR, and Tie2, implicate phosphorylation-dependent reverse signaling as a potential point of cross-talk between multiple signaling pathways (Bruckner et al. 1997; Adams et al. 1999; Chong et al. 2000; Palmer et al. 2002; Thelemann et al. 2005). Second, the C terminus of B-type ephrins constitutes a PSD-95/Dlg/ZO-1 (PDZ)-binding motif enabling a PDZ-dependent reverse signal (Torres et al. 1998; Lin et al. 1999). A few PDZ domain-containing proteins that can interact with the ephrin-B1 C terminus have been identified, although the in vivo relevance of these interactors in mediating ephrin-B reverse signaling is unknown (Torres et al. 1998; Lin et al. 1999; Lu et al. 2001). Phosphorylation and PDZ-dependent reverse signaling by ephrin-B1 have each been proposed to play important roles in multiple contexts in development and disease, but an in vivo analysis of the relative contributions of forward versus reverse signaling, and of PDZdependent versus phosphorylation-dependent reverse signaling has not been performed.

Mutations in the Ephrin-B1 gene result in a wide spectrum of developmental abnormalities constituting craniofrontonasal syndrome (CFNS) in humans (Twigg et al. 2004; Wieland et al. 2004). This syndrome includes a number of craniofacial anomalies including cleft palate, craniofrontonasal dysplasia, craniosynostosis, axial skeletal defects such as asymmetry of the thoracic skeleton and limb abnormalities, as well as neurological defects such as agenesis of the corpus callosum (ACC) and mental retardation. Although CFNS is an X-linked condition, it exhibits an unusual pattern of inheritance whereby females are more severely affected than males. Loss-offunction mutations of ephrin-B1 in mice have been shown to phenocopy multiple aspects of CFNS; homozygous mutant mice display cleft palate and craniofrontonasal dysplasia, and heterozygous mutant female mice display additional phenotypes not observed in males, including polydactyly, and frontal bone foramina (Compagni et al. 2003; Davy et al. 2004, 2006). Since ephrin-B1 is $\mathrm{X}$-linked, random $\mathrm{X}$ inactivation results in mosaic loss of function of ephrin-B1, depending on the allele inactivated. This mosaic loss of function is followed by ephrinmediated cell sorting, resulting in the formation of ectopic eph/ephrin boundaries and subsequent additional heterozygous phenotypes (Compagni et al. 2003; Davy et al. 2006).

Agenesis of the CC is a notable facet of CFNS, since Eph/ephrin signaling has been shown to be involved in axon pathfinding in numerous contexts. The telencephalic commissural axon tracts include the anterior commissure, the hippocampal commissure, and the CC; these provide neuronal connectivity to integrate information across the left and right hemispheres of the cerebral cortex (Paul et al. 2007). ACC is a congenital malformation that can occur as an isolated condition, or as part of at least 50 different human syndromes (Richards et al. 2004; National Institute of Neurological Disorders and Stroke's agenesis of the corpus callosum information page, http://www.ninds.nih.gov/disorders/agenesis/ agenesis.htm). Formation of the CC involves a complex, multistep process that requires the proper spatial and temporal distribution of numerous long- and short-range axon guidance cues, which may explain the high frequency of ACC. Some of these signals are provided by GFAP-expressing glial guidepost structures, which act as intermediate targets to channel callosal axons across the midline (Paul et al. 2007). The glial wedge (GW) and midline zipper glia (MZG) are positioned ventrally, and the indusium griseum (IG) glia is located dorsally to the CC axons. The GW forms first at the dorsomedial aspect of the lateral ventricles where it extends long radial processes that give it its wedge shape (Shu et al. 2003). The IG forms by somal translocation of radial glia from the ventricular zone to the midline where it differentiates (Smith et al. 2006). Axons avoid these guidepost structures in vivo, and the GW has been shown to provide repulsive influence in vitro by virtue of expression of the chemorepellant Slit2 (Shu and Richards 2001; Shu et al. 2003).

Although significant achievement has been made in identifying roles for eph/ephrin signaling in axon guidance during development, the molecular pathways by which these signaling molecules control axon guidance decisions in multiple developmental contexts continue to be elucidated. Particularly, a paucity of information exists regarding ephrin-mediated signal transduction in axon guidance, and the relative importance of forward or reverse signaling. In this study, we directly identify functional significance for ephrin-B1 reverse signaling during development by generating three targeted knock-in lines that independently ablate specific downstream reverse signal transduction pathways, while maintaining forward signaling capacity. We find that reverse signaling by ephrin-B1 is critical for a subset of its developmental roles, specifically axon pathfinding of the CC. Ephrin-B1 is expressed within CC axons, whereas EphB2 is most strongly expressed in glial guidepost cells. Ephrin-B1 localizes to the axon shaft and growth cone of cortical axons, and a subset of cortical axons avoid Eph2 in an in vitro stripe assay, indicating that reverse signaling can mediate guidance autonomously within cortical axons. This reverse signal does not require phosphorylation of the cytoplasmic tail, but instead relies on the binding of PDZ domain proteins for its transduction. These results demonstrate the context-specific importance of reverse signaling by ephrin-B1 during development and specify a PDZ-dependent molecular mechanism for its action.

\section{Results}

Generation of Ephrin-B1 reverse signaling mutants

To test the importance for ephrin-B1 reverse signaling during development, we generated three targeted point 
mutant mouse lines that abrogate reverse signaling conditionally by use of the Cre recombinase (Fig. 1A,B). The highly conserved intracellular domain is identical in the last 33 amino acids of the B-type ephrins, and includes a C-terminal PDZ-binding motif, and five conserved tyrosines, four of which have been shown to be phosphorylated (Fig. 1A; Holland et al. 1996; Bruckner et al. 1997; Lin et al. 1999; Kalo et al. 2001; Bong et al. 2004). Based on previous studies, binding of the signaling adaptor Grb4 to ephrin-B1 depends on phosphorylation of one of these tyrosines, Tyr-316 (Fig. 1A; Bong et al. 2004). An additional tyrosine residue is located just outside of this highly conserved region in Ephrin-B1 that is not present in Ephrin-B2 or Ephrin-B3. Ephrin-B1 is encoded by five exons, the last of which encompasses the entire intracellular domain, including the six intracellular tyrosines and the PDZ-binding motif. In each of the three targeting constructs, the wild-type fifth exon is floxed and followed in tandem by one of three mutant exons modified by site-directed mutagenesis. This strategy enables a wild-type ephrin-B1 protein to be made in the absence of Cre recombinase, and Cre-dependent removal of the wild-type fifth exon resulting in the production of the ephrin-B1 reverse signaling mutant protein (Fig. 1B). In the first construct, designated as ephrinB1 ${ }^{6 F}$, all of the intracellular tyrosines have been mutated to phenylalanine, thereby preventing phosphorylation-dependent reverse signaling. The ephrin $B 1^{\Delta V}$ mutant construct harbors a deletion of the conserved C-terminal valine that has been demonstrated to be critical for the binding of PDZ domain-containing proteins to both ephrin-B1 and ephrin-B2 (Lin et al. 1999; Makinen et al. 2005). It has been suggested that phosphorylation-dependent and PDZ-dependent reverse signaling may cooperate to achieve reverse signaling outcomes (Palmer et al. 2002; Su et al. 2004; Lee et al. 2009). To address this possibility, we also generated a mutant mouse line in which the intracellular tyrosines
Figure 1. Generation of ephrin-B1 reverse signaling mutant mice. (A) Schematic representation of ephrin-B1 reverse signaling mutant molecules indicating the 37 amino acids of the intracellular domain that include all six tyrosine residues and the C-terminal valine required for PDZprotein binding. The mutations indicated in bold were introduced into the fifth exon of ephrin-B1 and used for generation of the knock-in construct. (B) Strategy for the targeted conditional disruption of ephrinB1 reverse signaling. Each of three mutant fifth exons (ephrin- $B 1^{6 F}$, ephrin- $B 1^{\Delta V}$, and ephrin- $B 1^{6 F \Delta V}$ ) was independently inserted in tandem to a floxed wild-type fifth exon to allow Cre-conditional disruption of reverse signaling. An Asp718 site was introduced into the $3^{\prime} \mathrm{UTR}$ of all three mutant exons for the purpose of ES cell screening. External Southern probes are indicated by lines. The Neo expression cassette was FRT-flanked and inserted in reverse orientation into the fourth intron; its removal was accomplished by crossing to $\mathrm{Flp}^{\mathrm{e}}$ recombinase-expressing, ROSA26 $6^{\text {Flper }}$ mice. Cre-mediated removal of the wildtype fifth exon resulted in read-through to the mutant fifth exon, and generation of ephrin-B1 reverse signaling mutant proteins. The positions of the endogenous translation stop codons (S) are indicated. $(C)$ Southern blot hybridization of ES cell DNA digested with HindIII $(\mathrm{H})$ probed with the indicated $5^{\prime}$ external probe revealed an 8.2-kb wild-type band and 6.5-kb correctly targeted band, and ES cell DNA digested with Asp718 $(A)$ was probed with the indicated $3^{\prime}$ external probe revealing an $8-\mathrm{kb}$ wild-type band and a $6.3-\mathrm{kb}$ correctly targeted band.

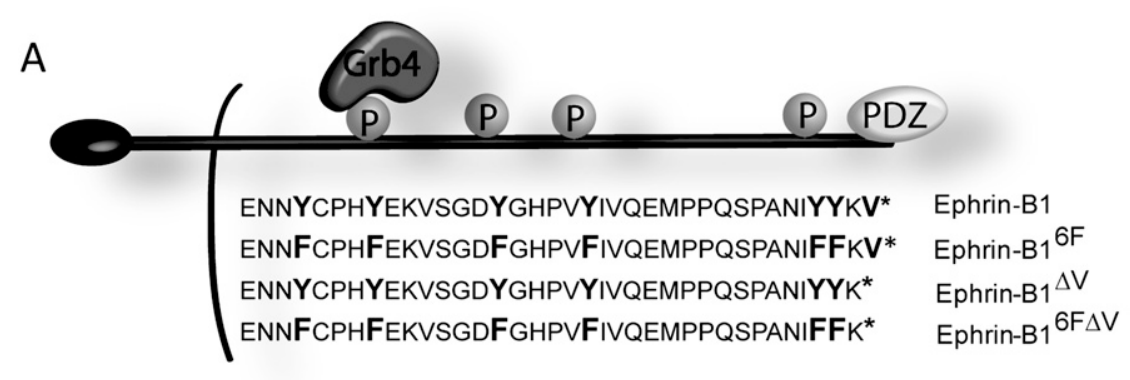

B
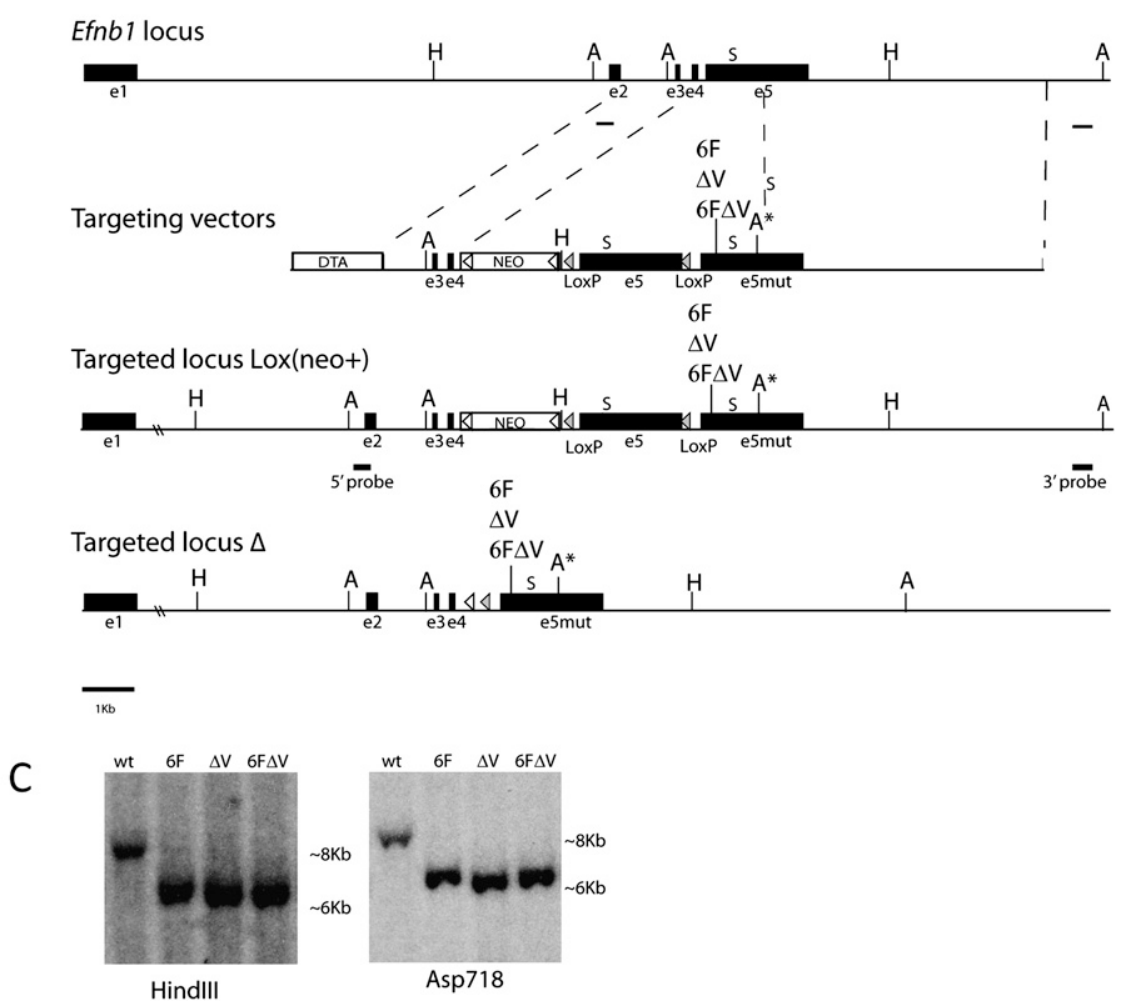
as well as the C-terminal valine have been mutated in cis (ephrin $B 1^{6 F \Delta V}$ ), abrogating all known mechanisms of signaling by the intracellular domain of ephrin-B1. Reverse signaling heterozygous and homozygous mutant females, as well as hemizygous mutant males, were viable and appeared healthy at all stages of development.

Previous work has demonstrated the importance of proper membrane localization for evaluation of reverse signaling function (Cowan et al. 2004; Makinen et al. 2005). To ensure that the ephrin-B1 point mutant proteins localized normally, we performed immunofluorescent antibody staining of ephrin-B1 in primary embryonic fibroblasts derived from embryonic day 13.5 (E13.5) mutant embryo secondary palatal shelves. Punctate membrane localization indistinguishable from wild type was observed for all three reverse signaling mutant lines (Fig. 2A-D). Additionally, to confirm that these mutations did not affect forward signaling, we immunoprecipitated EphB2 from E13.5 whole-embryonic lysates followed by immunoblotting with an antibody recognizing phos- phorylated tyrosine. Whereas the ephrinB1 $1^{\text {null }}$ immunoprecipitate showed significantly reduced tyrosine phosphorylation of the EphB2 receptor, each of the reverse signaling mutants demonstrated a wild-type level of EphB2 tyrosine phosphorylation (Fig. 2E), indicating that normal levels of forward signaling were maintained in reverse signaling mutants.

To confirm that the ephrin-B1 reverse signaling mutants performed as expected with respect to phosphorylationdependent reverse signaling, ephrin-B1 was immunoprecipitated from E13.5 embryonic head lysate, followed by immunoblotting with an antibody recognizing ephrin-B1. A shifted band in ephrin-B $1^{\text {wt }}$ lysates corresponds to tyrosine-phosphorylated ephrin-B1 (Fig. 2F). Stripping and reprobing with an antibody recognizing phosphorylated tyrosine confirmed the tyrosine phosphorylation status of this band (data not shown). As anticipated, this shift was lost in ephrin- $B 1^{6 F}$ and ephrin- $B 1^{6 F \Delta V}$ immunoprecipitates, but was preserved in ephrin-B1 $1^{\Delta V}$ mutants, whereas no ephrin-B1 was detected in the ephrin-B1 ${ }^{\text {null }}$
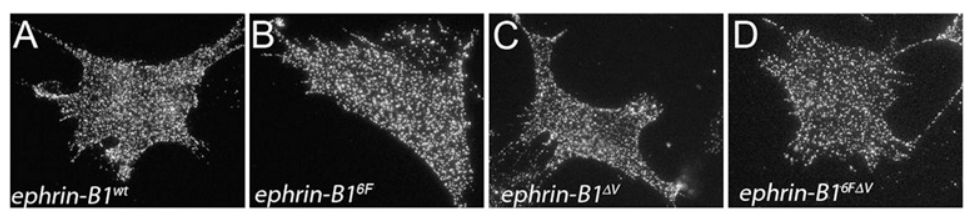

$\mathrm{E}$

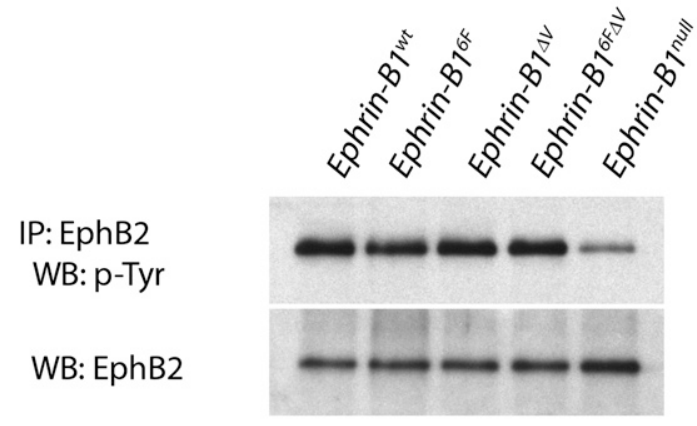

$\mathrm{F}$

$$
\begin{aligned}
& \text { IP: ephrin-B1 } \\
& \text { WB: ephrin-B1 } \\
& \text { WCL } \\
& \text { WB: } \alpha \text {-Tubulin }
\end{aligned}
$$

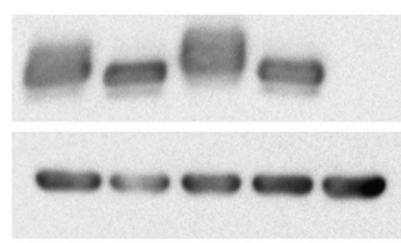

G

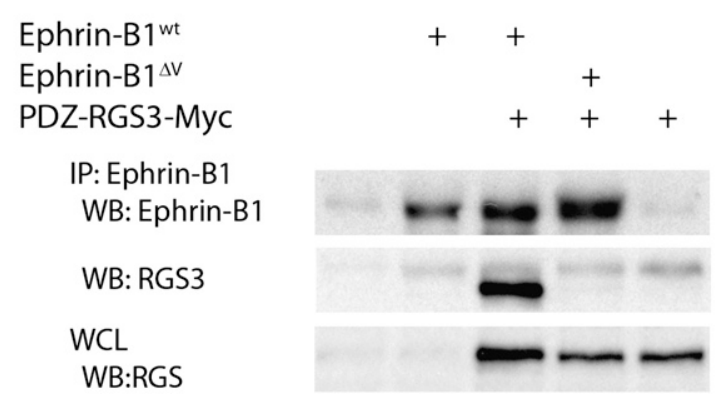

Figure 2. Validation of ephrin-B1 reverse signaling mutants. $(A-D)$ Immunofluorescent detection of membrane localization of ephrin-B1 in primary mouse embryonic fibroblasts (MEPMs) derived from palatal shelves of reverse signaling mutants. Identical localization of ephrin-B1 was detected in fibroblasts derived from $(A)$ ephrin- $B 1^{\text {wt }},(B)$ ephrin- $B 1^{6 F},(C)$ ephrin- $B 1^{\Delta V}$, and $(D)$ ephrin- $B 1^{6 F \Delta V}$. (E) Immunoprecipitation of EphB2 from E13.5 head lysate, followed by immunoblotting with antibodies recognizing phosphorylated tyrosine indicates reduced phosphorylation of EphB2 in ephrin-B1 $1^{\text {null }}$ embryos, whereas wild-type levels of phosphorylation were detected in ephrin- $B 1^{6 F}$, ephrin$B 1^{\Delta V}$, and ephrin- $B 1^{6 F \Delta V}$ reverse signaling mutants. $(F)$ Immunoprecipitation of ephrin-B1 from E13.5 embryonic head lysate followed by immunoblotting with antibodies recognizing ephrin-B1 revealed a band shift corresponding to ephrin-B1 phosphorylation in lysates from ephrin-B1 $1^{\text {wt }}$ and ephrin-B $1^{\Delta V}$ embryos, and loss of this shift in ephrin-B1 $1^{6 F}$ and ephrin- $B 1^{6 F \Delta V}$ mutant embryos; no ephrin-B1 was detected in ephrin-B1 ${ }^{\text {null }}$ lysates. $(G)$ 293T cells were transfected with expression vectors encoding PDZ-RGS3-Myc, and either ephrin$\mathrm{B} 1^{\mathrm{wt}}$ or ephrin-B1 ${ }^{\Delta \mathrm{V}}$. Lysates were immunoprecipitated with an anti-ephrin-B1 antibody, and immunoblotted with an anti-RGS3 antibody. PDZ-RGS3 coimmunoprecipitated with ephrin-B1 ${ }^{\mathrm{wt}}$ but not ephrin-B1 ${ }^{\Delta \mathrm{V}}$. 
mutant (Fig. 2F). These results confirm loss of phosphorylation-dependent reverse signaling by ephrin-B1 in ephrin- $\mathrm{B} 1^{6 \mathrm{~F}}$ and ephrin-B1 ${ }^{6 \mathrm{~F} \Delta \mathrm{V}}$ mutant embryos, and indicate the maintenance of phosphorylation-dependent reverse signaling in ephrin-B1 ${ }^{\Delta \mathrm{V}}$ mutant embryos. To verify that the ephrin-B $1^{\Delta V}$ mutation disrupted binding of ephrin-B1 to PDZ domain-containing proteins, we cotransfected $293 \mathrm{~T}$ cells with an expression construct encoding the previously identified ephrin-B1 interactor PDZRGS3-Myc, and an expression vector for ephrin-B1 or ephrin-B $1^{\Delta \mathrm{V}}$. As anticipated, immunoprecipitation of ephrin-B1 followed by immunoblotting for PDZ-RGS3 indicated that ephrin-B1 $1^{\text {wt }}$ coimmunoprecipitated PDZRGS3, whereas ephrin-B1 ${ }^{\Delta V}$ did not, confirming that this mutation disrupts PDZ-dependent reverse signaling (Fig. 2E).

\section{Ephrin-B1 reverse signaling is dispensable} for craniofacial and skeletal development

Ephrin-B1 complete loss of function results in multiple skeletal defects in ephrin-B1 ${ }^{\text {null }}$ mice, with additional phenotypic consequences resulting from ephrin- $B 1^{+/-}$ heterozygosity (Compagni et al. 2003; Davy et al. 2006). We therefore examined P0 skeletal preparations of each of the ephrin-B1 reverse signaling mutant mouse lines, compared with ephrin-B1 $1^{\text {null }}$ preparations. Ephrin-B1 $1^{\text {null }}$ mice are frequently born with a cleft secondary palate, malformations of the tympanic rings, and rib pairing defects (Fig. 3B,G,L). We found none of these skeletal malformations in ephrin- $B 1^{6 F}$, ephrin- $B 1^{\Delta V}$, or ephrin$B 1^{6 F \Delta V}$ mutant skeletons (Fig. 3). Ephrin- $B 1^{+/-}$female mice additionally display polydactyly and frontal bone foramen with nearly complete penetrance; these phenotypes were not observed in heterozygous ephrin-B1 reverse signaling mutant mice (Supplemental Fig. 1; Compagni et al. 2003; Davy et al. 2006). These results indicate that both PDZ-dependent and phosphorylationdependent ephrin-B1 reverse signaling are dispensable for skeletal development both alone and in cis, and suggest instead that forward signaling by ephrin-B1 may control the development of these structures.
Ephrin-B1 PDZ-dependent reverse signaling is required for formation of the CC

Eph/ephrin signaling has been well established as a critical regulator of axon guidance in multiple contexts (Egea and Klein 2007). Further, since EphB2 $2^{-/} ; E p h B 3^{-/-}$ double mutants display multiple axon tract malformations, we decided to inspect axon pathfinding in ephrin$B 1$ mutant brains (Orioli et al. 1996; Mendes et al. 2006). Coronal histological sections of P0 ephrin- $B 1^{\text {null }}$ brains revealed complete ACC along its entire rostrocaudal extent (Fig. 4B,G). Failure of the axons to cross was accompanied by the appearance of stereotypical Probst bundles of axons accumulating lateral to the midline (Fig. 4B). Additionally, in many cases, we observed aberrant projection of CC tract axons ventrally along the ipsilateral septum. By examination of serial sections we determined that these ectopic axon tracts migrated along the ventral edge of the diagonal band and then dorsocaudally through the internal capsule (Fig. 4L,M). This extension of aberrantly projecting axons suggests that axon outgrowth is not defective in ephrin-B $1^{\text {null }}$ mutant mice, but rather that axons are inappropriately redirected at the midline instead of forming an intact CC.

To determine whether the role for ephrin-B1 in the formation of the CC depended on forward, or reverse signaling, we examined ephrin- $B 1^{6 F \Delta V}$ reverse signaling mutants at P0. Histological sections revealed complete ACC in ephrin-B1 $1^{6 F \Delta V}$ mutant homozygous and hemizygous brains with high penetrance, indicating that reverse signaling by ephrin-B1 is critical for controlling the development of this axon tract (Fig. 4E,J; Table 1). We next investigated phosphorylation-dependent reverse signaling mutants in which PDZ-dependent reverse signaling is maintained. Ephrin-B1 $1^{6 F}$ mutant brains appeared normal, indicating that phosphorylation of ephrin-B1 is not required for formation of a normal CC. ACC was observed in ephrin-B $1^{\Delta V}$ mutant brains, however, indicating that disruption of PDZ-dependent reverse signaling was sufficient to cause this phenotype when phosphorylationdependent reverse signaling capacity was maintained. Further, since the penetrance and severity of ACC were

Figure 3. Ephrin-B1 reverse signaling is not required for craniofacial or skeletal development. $(A-E)$ Ventral views of skeletal preparations of neonatal skulls reveal a cleft secondary palate in ephrin-B $1^{\text {null }}$ (arrowheads and asterisks in $B$ ) compared with ephrin-B1 $1^{\text {wt }}$ mutant skulls. Normal palate development was observed in ephrin- $B 1^{6 F}$ $(C)$, ephrin-B1 $1^{\Delta V}(D)$, and ephrin-B1 ${ }^{6 F \Delta V}(E)$ mutant mice. $(F-J)$ Tympanic ring malformations are observable in ephrin-B1 $1^{\text {null }}$ mutants (red arrowhead in $G$ ), whereas

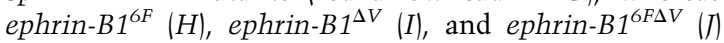
were indistinguishable from ephrin- $B 1^{\text {wt }}(A)$. $(K-O)$ Rib pairing and sternum malformations found in ephrin$B 1^{\text {null }}(L)$ were not found in ephrin- $B 1^{6 F}(M)$, ephrin$B 1^{\Delta V}(N)$, or ephrin-B1 $1^{6 F \Delta V}(O)$ mutant skeletons.

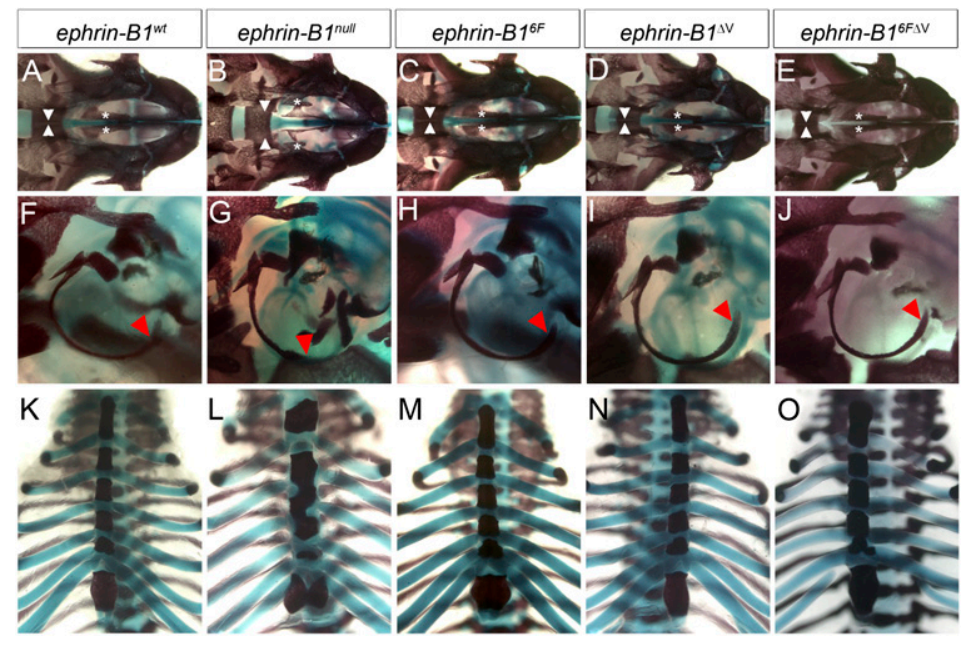




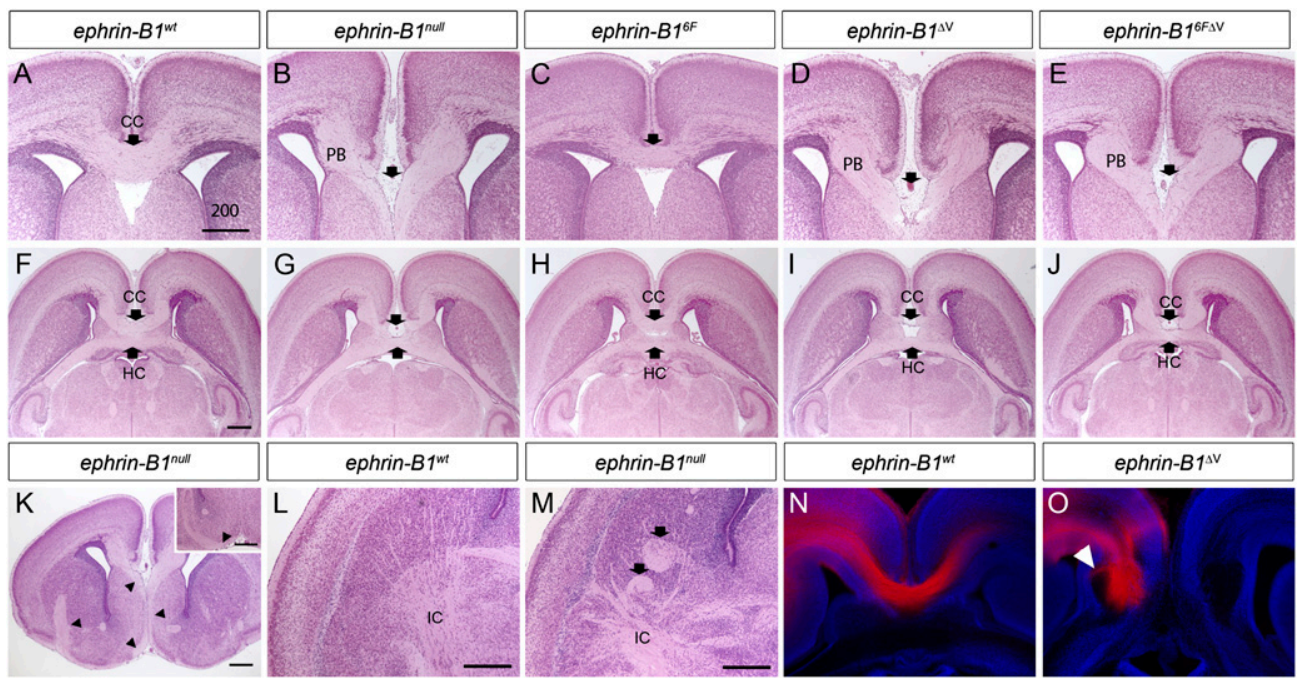

Figure 4. Histological analysis of agenesis of the corpus callosum $(C C)$ in ephrin-B1 mutant brains. $(A-E)$ Coronal sections of P0

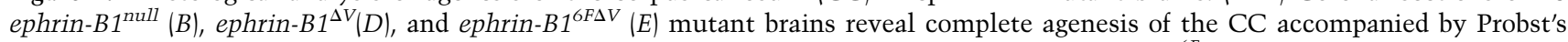

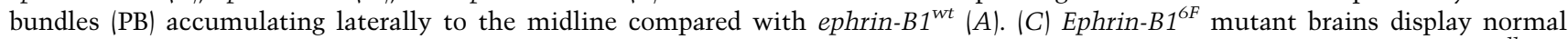
formation of the CC. The position of the CC is indicated by arrows. $(F-J)$ Horizontal sections of P0 ephrin-B1 $1^{\text {wt }}(F)$, ephrin-B1 ${ }^{\text {null }}(G)$,

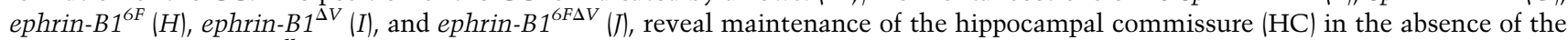
CC. $(K-M)$ Ephrin-B1 ${ }^{\text {null }}$ mutant histological sections demonstrating aberrantly migrating axons. Serial sectioning of mutant brains indicates that aberrantly migrated axons migrate ventrally through the septum, along the ventral edge of the diagonal band $(K)$, and back dorsocaudally (inset in $K$ ) through the internal capsule shown in horizontal sections in ephrin- $B 1^{\text {null }}$ mutant $(M)$ compared with ephrin$B 1^{w t}(L)$. $(N, O)$ DiI crystals placed in the dorsomedial cortex trace CC axons in ephrin- $B 1^{w t}(N)$, and ephrin-B1 $1^{\Delta V}$ mutant brains $(O)$ at E17.5. Bundles of axons have begun to accumulate at this stage, and wandering axons are indicated by arrowhead. Bar, $200 \mu \mathrm{m}$.

comparable in ephrin- $B 1^{\Delta V}$ and ephrin- $B 1^{6 F \Delta V}$ mutants, we deduce that phosphorylation of ephrin-B1 is not likely to influence PDZ-dependent reverse signaling (Table 1). Three of five PDZ-dependent reverse signaling heterozygous mutant females displayed ACC, and Ephrin-B1 ${ }^{+-}$ heterozygous mice displayed ACC in all cases examined $(n=3)$ (Table 1).

To begin to better understand the basis for this phenotype, we examined axonal trajectory in PDZ-dependent reverse signaling mutants using the lipophilic dye tracer, DiI. DiI tracing in wild-type embryos at E17.5 indicated significant crossing of axon fibers across the $\mathrm{CC}$ at this stage (Fig. 4N). CC axons in ephrin-B1 ${ }^{\Delta V}$ mutant embryos, however, failed to cross the midline and had begun to accumulate in ipsilateral bundles. The CC also appeared defasciculated and wandering axon fibers were visible (arrowhead in Fig. 4O).

Since Eph/ephrin signaling is involved in axon guidance in multiple contexts, we examined the formation of other axon tracts during development. Notably, EphB2 $2^{-/}$ mutants display defects of the lateral projection $(\mathrm{acP})$ of the anterior commissure, which are not recapitulated in mutants lacking only forward signaling by EphB2 (Henkemeyer et al. 1996). Normal formation of the anterior commissure occurred in all ephrin-B1 reverse signaling mutants (Supplemental Fig. 2), indicating that this process is likely to be controlled by reverse signaling through a different B-type Ephrin. This is consistent with a previous study demonstrating that ephrin-B2 lacking the intracellular domain leads to defects in formation of the anterior commissure, and suggests that reverse sig- naling by ephrin-B2 and not ephrin-B1 fills this developmental role (Cowan et al. 2004). We did not detect any other overt defects in axon pathfinding in the brain, and found no defects in the formation or pathfinding of peripheral or cranial ganglia in E11.5 ephrin-B ${ }^{6 F \Delta V}$ mutant embryos (Supplemental Fig. 2). Together, these results indicate that ephrin-B1 PDZ-dependent reverse signaling may play a specific role in axon pathfinding within the $\mathrm{CC}$ rather than a more general role in axon guidance.

Ephrin-B1 PDZ-dependent reverse signaling is critical for localization of GFAP-expressing glial guideposts

The ACC phenotype in ephrin- $B 1^{\Delta V}$ reverse signaling mutants was highly penetrant in $129 S 4$ mice, and highly

Table 1. Phenotypic frequency of ACC in ephrin-B1 mutant mice (in 129 S4 background, except where otherwise stated)

\begin{tabular}{|c|c|}
\hline Genotype & $\begin{array}{c}\text { Number displaying } \\
\text { ACC/observed }\end{array}$ \\
\hline ephrin-B $1^{w t}$ & $0 / 16$ \\
\hline ephrin-B1 $1^{\text {null }}$ & $4 / 4$ \\
\hline \multicolumn{2}{|l|}{ ephrin-B1 $1^{\text {null }}$} \\
\hline (129S4.C57BL/6J) & $0 / 3$ \\
\hline ephrin-B1 $1^{+/-}$ & $3 / 3$ \\
\hline ephrin-B $1^{6 F}$ & $0 / 5$ \\
\hline ephrin-B $1^{\Delta V}$ & $8 / 10$ \\
\hline ephrin-B1 ${ }^{\Delta V /+}$ & $2 / 2$ \\
\hline \multicolumn{2}{|l|}{ ephrin-B $1^{\Delta V}$} \\
\hline$(129 S 4 . C 57 B L / 6 J)$ & $0 / 3$ \\
\hline ephrin-B $1^{6 F \Delta V}$ & $12 / 14$ \\
\hline ephrin-B1 ${ }^{6 F \Delta V /+}$ & $1 / 3$ \\
\hline
\end{tabular}


dependent on genetic background. Ephrin-B1 ${ }^{\text {null }}$ mutant mice on a mixed C57BL/6J.129S4 genetic background did not display ACC $(n=3)$, and similarly, ephrin- $B 1^{\Delta V} \mathrm{~F} 1$ C57BL/6J.129S4 mice displayed a well-formed CC ( $n=3)$ (Table 1). A predisposition toward spontaneous defects of the CC has been documented for some 129 inbred strains; however, we never observed spontaneous ACC in any ephrin-B $1^{\text {wt }}$ mice in the $129 S 4$ inbred genetic background that we used for this study $(n=16)$ (Table 1; Wahlsten et al. 2006). Considering this genetic background dependence, we characterized the timing of formation of the CC in 129S4 mice. We found that crossing of the CC, and formation of GFAP-positive midline glia occurred 1 day later than reported for other genetic backgrounds, and later than embryos in the $C 57 B L / 6 J . C B A / J$ hybrid background (Fig. 5; Supplemental Fig. 3).

Since the localization of glial guidepost cells is critical for the normal formation of the CC, we examined the development of these structures in ephrin- $B 1^{\Delta V}$ reverse signaling mutants. At E16.5, just prior to crossing of CC axons, we could detect no differences in the migratory progress of axons of the CC in ephrin-B1 ${ }^{\Delta V}$ mutant embryos (Fig. 5A-D). Further, no defects in the midline fusion of the telencephalic hemispheres had occurred. At this stage, we found that the GFAP-expressing GW and MZG were indistinguishable from wild type, indicating that the initial formation of the GW was normal (Fig. 5AD). At E17.5, however, whereas axon crossing had begun in ephrin-B $1^{\text {wt }}$ embryos, axon extension had stalled and began to collect in bundles lateral to the midline in ephrin- $B 1^{\Delta V}$ mutant embryos (Fig. 5E,F). This was accompanied by a mislocalization of GFAP-expressing guidepost cells at the midline in the path where CC axons were destined to migrate as well as within the forming Probst bundles of axons (Fig. 5E-H). It was not possible to definitively distinguish dorsal midline IG from ventral MZG glia in the absence of the crossing of CC axons. We additionally observed a distorted appearance and in some sections noted an apparent decrease in GFAP-expressing cells of the GW as callosal axon bundles accumulated (Fig. $5 \mathrm{G}-\mathrm{J})$. The GW has been shown to provide repulsive influence on callosal axons as they turn toward the midline by virtue of the expression of Slit2, a diffusible ligand for the axonally expressed Robo receptors (Shu and Richards 2001). Disrupted expression of Slit2 in the ephrin- $B 1^{\Delta V} \mathrm{GW}$, therefore, could result in aberrant guidance of CC axons as they turn toward the midline. We detected no difference in the expression of Slit2 within the GW between ephrin-B $1^{w t}$ and ephrin- $B 1^{\Delta V}$ brains at E17.5, by in situ hybridization, indicating that repulsive action of the GW mediated by Slit 2 was maintained (Fig. 5K,L).

\section{Ephrin-B1 and EphB2 expression during formation of the $C C$}

Ephrin-B1 has been reported to be expressed during CC formation (Mendes et al. 2006). Therefore, we sought to confirm and extend this expression analysis to better understand the role that ephrin-B1 reverse signaling may be playing. We examined expression of ephrin-B1 and its

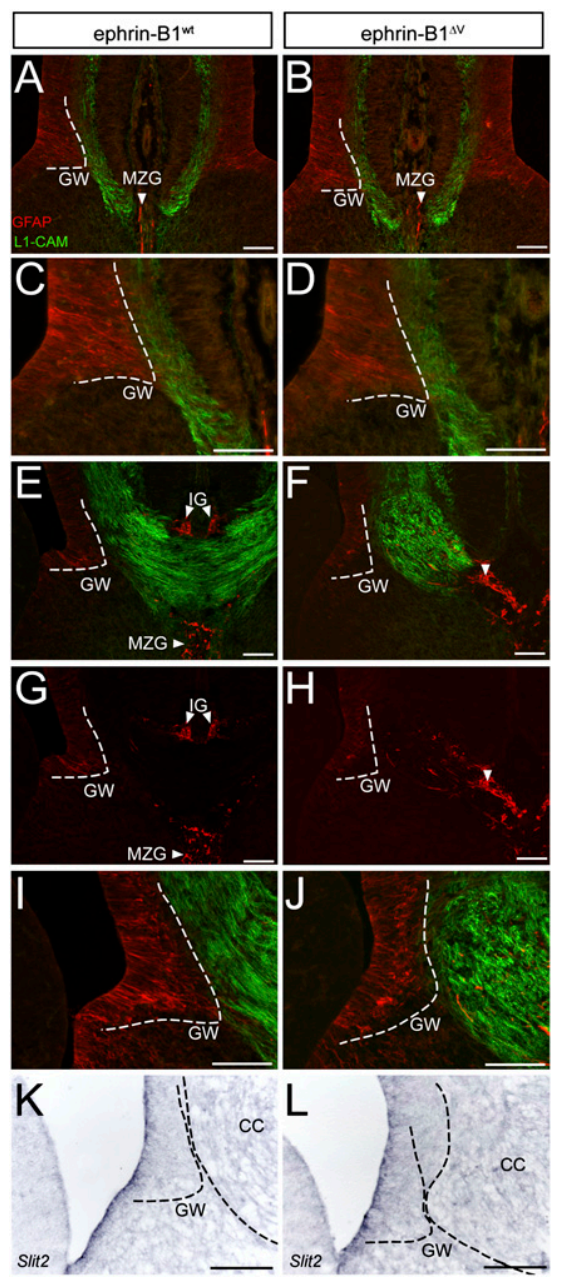

Figure 5. Loss of PDZ-dependent ephrin-B1 reverse signaling results in aberrant migration of $\mathrm{CC}$ axons and midline glia mislocalization. (A-I) Antibody staining against L1-CAM (green) and GFAP (red) during formation of the CC. Migration of CC axons and initial formation of the GW and MZG guidepost structures are normal at E16.5 in ephrin-B1 ${ }^{\Delta V}$ mutant brains $(B, D)$, compared with ephrin-B1 $1^{w t}(A, C) .(E, F)$ At E17.5, axons of the CC have stalled lateral to the midline, and have begun to form bundles in ephrin-B1 ${ }^{\Delta V}$ mutant brains $(F)$ compared with ephrin-B1 $1^{\text {wt }}(E)$, which displays significant crossing of the CC at this stage. A distorted and reduced appearance of GFAP-positive cells of the GW coincides with the accumulation of axon bundles in ephrin-B1 $1^{\Delta V}(F, J$, higher magnification in $J)$ compared with the well-extended wedge shape in ephrin-B $1^{w t}(E, G$, higher magnification in $I$ ). Collapse of GFAP-positive cells of the IG (arrowhead in $H$ ) was associated with their aberrant midline localization in ephrin-B $1^{\Delta V}$ mutants $(F, H)$, compared with a dorsally localized IG in ephrin- $B 1^{\text {wt }}$ brains $(E, G) .(K, L)$ Slit2 mRNA expression appears unperturbed in the GW of ephrin-B1 $1^{\Delta V}$ mutant $(L)$, when compared with ephrin-B $1^{\text {wt }}(K)$ at E17.5. Bar, $100 \mu \mathrm{m}$.

receptors at multiple stages during this developmental process by antibody staining. Ephrin-B1 was strongly expressed throughout the cortex between E13.5 to E18.5 with expression within the ventricular and intermediate zones and radial glia (Fig. 6A-H). Notably, we found 

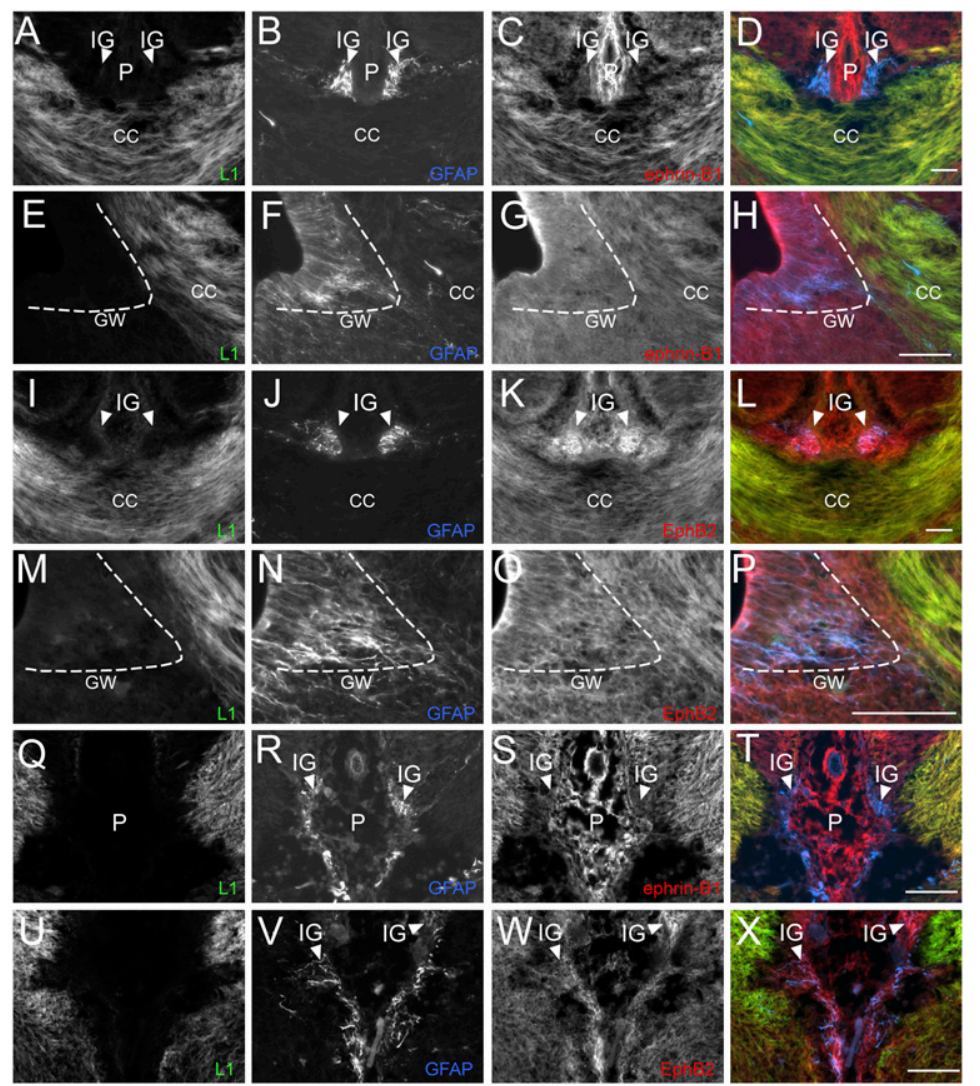

Figure 6. Expression of ephrin-B1 and EphB2 during midline crossing of the CC. $(A-H)$ Expression of ephrin$\mathrm{B} 1$ in the wild-type E18.0 CC. Ephrin-B1 $(C)(\mathrm{red})$ is coexpressed with L1-CAM $(A)$ (green) in axons of the CC $(A, C, D)$, but not within GFAP-expressing IG glia (blue) $(B-D)$. Expression of Ephrin-B1 can be detected within the subventricular zone (SVZ) $(G, H)$, and some expression can be detected within the GW $(F-H)$. $(I-P)$ EphB2 expression in the wild-type E18.0 CC. $(M-T)$ EphB2 is strongly coexpressed with GFAP within IG glia cells $(J, K)$, and more weakly within L1-CAM-expressing cells of the CC $(I, K, L)$. Coexpression of EphB2 with GFAP within cells of the GW was also observed $(N-P)$. $(Q-T)$ Ephrin-B1 expression in E17.5 ephrin-B1 ${ }^{\Delta V}$ mutant brain. Ephrin-B1 is coexpressed with L1-CAM within noncrossing CC axons $(Q, S, T)$, but not within mislocalized GFAP-positive IG cells $(R-T) .(U-X)$ EphB2 expression in E17.5 ephrin- $B 1^{\Delta V}$ mutant brain. EphB2 is coexpressed within mislocalized GFAP-positive midline glia $(V-X)$. Bar, $100 \mu \mathrm{m}$. (P) Interhemispheric pia. strong expression of ephrin-B1 within axons of the CC, as indicated by coexpression with the axon marker L1-CAM both before and during crossing (Fig. 6A-D; Supplemental Fig. 4D-F). Ephrin-B1 was coexpressed with GFAP within many, but not all cells of the GW at E16.5 before axon crossing and at E17.5 after crossing had begun (Supplemental Fig. 4G-I; Fig. 6E-H). Ephrin-B1 expression was absent from the GFAP-expressing cells of the IG and from the $M Z G$, and was strongly expressed within interhemispheric pial membrane cells (Fig. 6A-D; Supplemental Fig. 4D-F).

Since ephrin- $B 1^{\Delta V}$ mutant brains exhibited significant mislocalization of IG and MZG cells, we sought to examine whether glial localization might be autonomously regulated by ephrin-B1 reverse signaling. If so, ephrin-B1 would be expected to be expressed within these mislocalized glial cells. We found no coexpression of ephrin-B1 with GFAP in mislocalized glial populations in E17.5 ephrin-B1 ${ }^{\Delta V}$ mutant brains, whereas ephrin-B1 was expressed normally within the axons and VZ of ephrin-B1 $1^{\Delta V}$ mutant mice (Fig. 6Q-T). The lack of expression of ephrin-B1 within midline mislocalized glial cells suggests that this mislocalization is not an autonomous consequence of loss of ephrin-B1 reverse signaling.

EphB2; EphB3 compound null mutants display many of the same phenotypes as ephrin-B1 ${ }^{\text {null }}$ embryos, including ACC. We therefore examined expression of EphB2 and EphB3 during formation of the CC by antibody staining in sections (Orioli et al. 1996). EphB3 expression at E17.5 was weak and broadly distributed; comparison with primary-excluded antibody controls and with E13.5 positive control sections indicated efficacy of the antibody staining (data not shown). In contrast, EphB2 was robustly expressed in GFAP-expressing cells of the IG at E17.5, and overlapping with GFAP-expressing cells of the GW, with weaker expression detected in callosal axons (Fig. 6I-P). EphB2 was also detected within the MZG, GW, and CC axons just prior to axon crossing at E16.5 (Supplemental Fig. 4M-R). EphB2 was expressed normally within mislocalized midline glia in E17.5 ephrin$B 1^{\Delta V}$ mutant brains (Fig. 6U-X). The strong expression of EphB2, and relatively weak expression of EphB3 are consistent with recently published data indicating that most EphB2 homozygous null mutants display defects in the CC, whereas EphB3 homozygotes do not, indicating that EphB2 may be a more significant signaling partner for ephrin-B1 in the formation of the CC (Mendes et al. 2006). Further, the striking expression of EphB2 within the IG glia, and expression of ephrin-B1 within callosal axons, suggests a potential guidance relationship mediated by reverse signaling between Eph-expressing IG glia and ephrin-expressing axons.

\section{Engagement of Ephrin-B reverse signaling in cortical axons mediates an avoidance response to EphB2}

Axon pathfinding is facilitated at the cellular level by the dynamic action of a highly motile and sensitive growth 
cone that serves to detect and respond to both repulsive and attractive molecular guidance cues (Dickson 2002). For reverse signaling to play an autonomous role within axons of the CC, ephrin-B1 should be localized within growth cones of cortical axons. Consistent with such a role for ephrin-B1 reverse signaling, ephrin-B1 expression in cortical explant cultures was localized in puncta along the length of $\beta$-tubulin-positive axons, and within growth cones of many axons $(\sim 50 \%)$ extending from cortical explants (Fig. 7A-C). Ephrin-B1 localization in
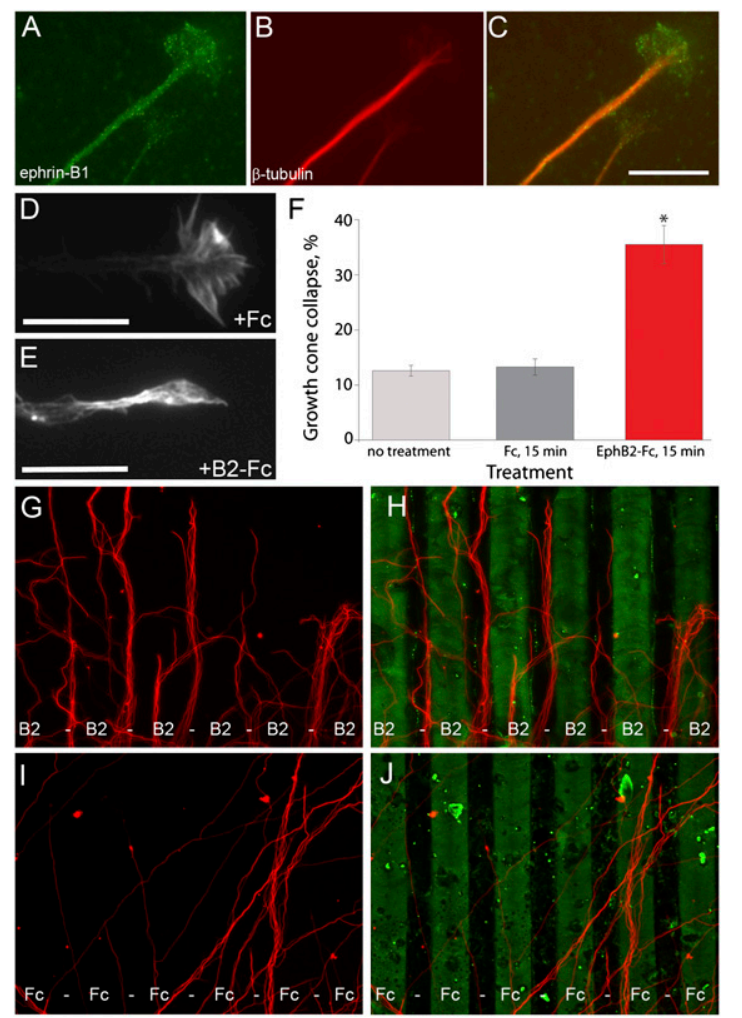

Figure 7. Activation of Ephrin-B reverse signaling autonomously within cortical axons mediates an axon guidance response. $(A-C)$ Immunostaining of cortical explant cultures indicates localization of ephrin-B1 within cortical axons. Punctate expression of Ephrin-B1 $(A, C)$ was detected within $\beta$-tubulinexpressing $(B, C)$ neurons along the length of axon shafts and within cortical axon growth cones. Bar, $10 \mu \mathrm{m}$. $(D-F)$ Activation of Ephrin-B reverse signaling results in increased growth cone collapse in cortical explant culture. Examples of well-spread growth cone morphology from a control Fc-treated $(D)$, and collapsed growth cone morphology from an EphB2-Fc- treated explant $(E)$, stained with rhodamine phalloidin. Bar, $10 \mu \mathrm{m} .(F)$ Quantification of growth cone collapse activity in EphB2-Fc or control Fc-treated explants each from three independent wells indicates significant growth cone collapse in response to EphB2Fc treatment. $\left(^{\star}\right) P<0.001$, one-way ANOVA. $(G, H)$ In a subset of cortical explants (six out of 62) grown on carpets of alternating stripes of EphB2-Fc (green) $\beta$-tubulin-positive axons (red) avoided EphB2-Fc stripes. $(I, /)$ This effect was never observed (zero out of 58) on carpets of alternating stripes of Fc alone (green), on which $\beta$-tubulin-positive axons (red) displayed random growth. growth cones and shafts of ephrin- $B 1^{\Delta V}$ mutant axons was indistinguishable from wild type (data not shown).

Eph/Ephrin signaling molecules have been characterized as both repulsive and attractive axon guidance cues in various contexts both in vitro and in vivo (Dickson 2002; Egea and Klein 2007). We therefore asked how expression of EphB2 on glial guidepost cells might be influencing ephrin-B1-expressing CC axons. Since ephrin-B reverse signaling is capable of receiving a repulsive cue in other contexts (Birgbauer et al. 2001; Mann et al. 2003), we decided to test whether this might be the case in cortical axons. Growth cone collapse is frequently utilized as a sensitive indicator of repellant capacity (Kapfhammer et al. 2007). We therefore tested whether activation of ephrin-B reverse signaling could provide repellent activity in cortical explant culture. Treatment with EphB2-Fc resulted in moderate growth cone collapse behavior after $15 \mathrm{~min}$, whereas no treatment or treatment with Fc alone resulted in well spread growth cone morphology $(P<0.001)$ (Fig. 7D-F). To further test the guidance response of cortical axons to ephrin-B1 reverse signaling we adapted a widely used substratum choice stripe assay for use with cortical explants (Knoll et al. 2007). Cortical explants were isolated and placed on carpets of alternating stripes of EphB2-Fc, or on carpets of alternating Fc stripes alone, and axon outgrowth was allowed to proceed in culture for $48 \mathrm{~h}$. Whereas explants were unresponsive to Fc control stripes in all cases (zero out of 58 ), $\sim 10 \%$ (six out of 62 ) of explants extended a field of axons that displayed striking avoidance of EphB2-Fc stripes (Fig. 7D-G). This repulsive response to EphB2-Fc is consistent with a role for ephrin-B1 PDZdependent reverse signaling in the axons of the CC.

\section{Discussion}

Our results demonstrate a specific requirement for ephrinB1 PDZ-dependent reverse signaling in a subset of the developmental contexts that require ephrin-B1 function. We find that PDZ-dependent reverse signaling by ephrin$\mathrm{B} 1$ is necessary for normal axon guidance of the CC in the mammalian telencephalon. Multiple mutations in the human Ephrin-B1 gene have been indentified in humans with CFNS, an X-linked congenital disorder that frequently includes ACC (Twigg et al. 2004; Wieland et al. 2004). Interestingly, most of the mutations characterized to date are located in exons encoding the extracellular domain of Ephrin-B1 (Wieland et al. 2005). These include frameshift, nonsense, and splice site mutations that would cause premature termination of translation and would likely result in nonsense-mediated mRNA decay, and therefore exhibit loss of both forward and reverse ephrin-B1 signaling function. Two frameshift mutations predicted to extend the $\mathrm{C}$ terminus of ephrin-B1 by 44 amino acids have been identified in CFNS patients; these may disrupt the ability of Ephrin-B1 to cluster and therefore execute forward signaling normally. The predominance of mutations in exons encoding the extracellular domain of Ephrin-B1 is not surprising in light of our finding that Ephrin-B1 reverse signaling is not required 
for craniofacial or skeletal development. It is possible, therefore, that mutations in the intracellular domain of Ephrin-B1 may underlie a category of "nonsyndromic" ACC cases, in addition to those that result in ACC as part of the CFNS syndrome.

ACC is a common congenital malformation, and can result from perturbation of this complex developmental process in several distinct ways. In embryos lacking ephrin-B1 signaling function, axons of the CC approach the midline, but never cross, and result in both the formation of Probst bundles and aberrant ventral migration of callosal axons. Our expression analysis suggests a guidance relationship whereby signal from EphB2expressing IG or GW glia may be transduced to ephrinB1-expressing CC axons at the midline. Indeed, we find that in two independent assays, cortical axons displayed avoidance behavior to EphB2. The fact that not all explants displayed a response to EphB2 stripes in our stripe assay likely reflects heterogeneity inherent in these cortical explant cultures; not all projections would be callosal axons and thus might not be expected to respond to an Ephrin-B reverse signal stimulus. Whereas the repulsive action of Eph/ephrin forward signaling in axon guidance has been thoroughly documented, the influence of reverse signaling on axon behavior is less characterized. Evidence for a repulsive axon guidance response mediated by ephrin-B1 reverse signaling has been presented in Xenopus embryonic retinal axons treated with EphB2-Fc causing rapid collapse of retinal axon growth cones (Mann et al. 2003). Similarly, mouse retinal axons exhibit collapse when confronted with soluble EphB1, EphB2, or EphB3, and avoid substratum-bound spots of EphB-Fc (Birgbauer et al. 2001). Pathfinding of dorsal retinal ganglion cell axons requires EphB receptor function, but not kinase activity, indicating that Ephrin-B reverse signaling mediates axon guidance through a repulsive mechanism in this context as well (Birgbauer et al. 2000). The reverse signaling mechanism utilized to achieve axon guidance outcomes in these contexts has not yet been defined; our data indicate that a PDZdependent pathway may be responsible.

How would a repulsive signal from midline glial guideposts result in failure of the CC to form? Expression of the chemorepellant Slit2 within IG and GW cells serves to provide a channel through which Robo-expressing axons must migrate (Shu and Richards 2001). Loss of this repulsive corridor in Slit2 homozygous mutant mice resulted in misrouting of callosal axons ventrally into the septum (Bagri et al. 2002; Richards 2002). We observed a similar ventral misrouting of callosal axons along the septum in ephrin-B1 mutant mice, suggesting that EphB2 signaling from guidepost glia may also provide a "surround repulsion" channel through which ephrin-B1-expressing axons are guided (Fig. 8). It is possible that defective midline glial guidepost development contributes to the ACC phenotype we observe. Multiple repulsive axon guidance cues would be expected to be expressed within mislocalized glial guidepost cells, and their mislocalization could contribute to the ACC phenotype we observed in ephrin-B1 mutant brains. Lack

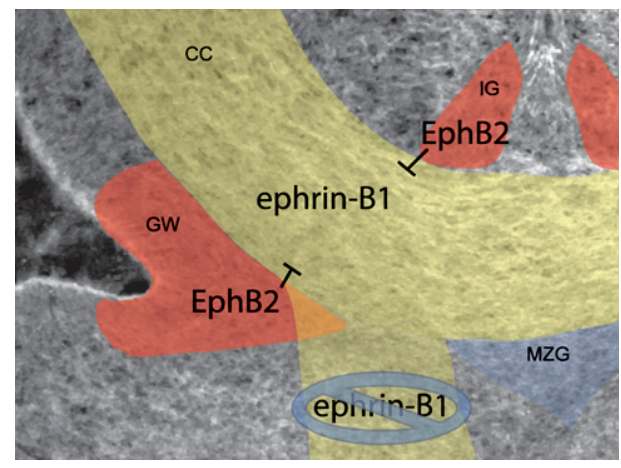

Figure 8. Model for Ephrin-B1 reverse signaling action in formation of the CC. Axons expressing ephrin-B1 (yellow) are guided by surrounding repulsion provided by guidepost glia expressing EphB2 (red). In the absence of the ability of ephrin-B1expressing axons to receive this signal (ephrin- $B 1^{\Delta V}$ mutants), axons do not cross the midline, and instead migrate ventrally along the septum.

of expression of ephrin-B1 in the IG or MZG of ephrin$B 1^{\text {wt }}$ brains, or within mislocalized midline glial cells in ephrin- $B 1^{\Delta V}$ mutant brains, however, indicates that this mislocalization is not likely to be the most proximal consequence of loss of reverse signaling. Formation of the GW also appeared normal in ephrin- $B 1^{\Delta V}$ mutant embryos, although its shape was later perturbed in acolossal ephrin-B1 ${ }^{\Delta V}$ mutant brains. This loss of GW fidelity could result in a decrease in other axon guidance signals that provide repulsive cues to axons as they turn toward the midline. We could not detect a difference in Slit2 expression in the GW of ephrin-B1 $1^{\Delta V}$ mutant brains, however, indicating that Slit2/Robo signaling from the GW is unlikely to be involved.

Multiple Eph/ephrin signaling molecules play an important role at the midline during CC formation (Mendes et al. 2006). Transgenic expression of a truncated, kinaseinactive EphA5 mutant receptor in mice resulted in defects in the projection of a subset of CC axons $(\mathrm{Hu}$ et al. 2003). Although it is not known whether this transgene effects forward or reverse signaling, it is clear that perturbation of EphA/ephrin-A signaling has consequences in $\mathrm{CC}$ formation. More recent work has identified the receptor/ligand pair of EphB1/ephrin-B3, as being critical for cortical axon outgrowth and formation of the CC (Mendes et al. 2006). Interestingly, in both $E p h B 1^{K O / K O}$ homozygous, and Ephrin-B3 $3^{K O / K O}$ homozygous mutants, a dramatic mislocalization of glial guideposts was observed, indicating that this may be a somewhat common attribute of complete ACC. Notably, this signaling pair seems to work through forward signaling from ephrin-B3 (expressed in glial guideposts) to EphB1 (expressed in the axons), since mice deficient in reverse signaling by ephrin-B3 do not display this phenotype. Ephrin-B1 can bind EphB1, although compound mutant analysis of mice with mutations in EphB1 and EphB2, or ephrin-B3 and EphB2, suggest that these two signaling pathways may work independently and by different signaling mechanisms (forward vs. reverse) (Blits-Huizinga et al. 2004; Mendes et al. 2006). The high 
degree of background dependence of the CC phenotype suggests the possible existence of a mechanism for compensation that depends on other B-type ephrins. Whereas ephrin-B3 reverse signaling is not required for formation of the CC, ephrin-B2 is also highly expressed in $\mathrm{CC}$ axons, although a role for ephrin-B2 in the CC has not yet been explored (Mendes et al. 2006). Regardless, multiple members of Eph/ephrin signaling families and genetic interactions between them may well be necessary for formation of the CC.

We find that reverse signaling by ephrin-B1 is not required for normal craniofacial or skeletal development. These findings fit well with recently published results indicating that EphB2 $2^{\mathrm{LacZ} / \mathrm{LacZ}} ; \mathrm{EphB}^{-/-}$mutant mice that maintained reverse but not forward signaling capacity displayed cleft palate with similar penetrance to EphB2 $2^{-/-}$, EphB3 ${ }^{-/-}$-null mutants, but did not display ACC (Mendes et al. 2006; Risley et al. 2008). Taken together, these analyses indicate that ephrin-B1 forward signaling through EphB2 and EphB3 is both necessary (Risley et al. 2008) and sufficient (this study) for normal palatogenesis. Conversely, PDZ-dependent reverse signaling from EphB2 to ephrin-B1 is both necessary (this study) and sufficient (Mendes et al. 2006) for formation of the CC. This indicates that a simultaneously bidirectional ephrin-B1-EphB2/B3 signal may not be necessary for development, but rather that ephrin-B1 serves either as a receptor or ligand depending on context. This interpretation is consistent with studies with other B-type ephrins, since reverse signaling is dispensable for early ephrin-B2 vascular function, but is critical for formation of the anterior commissure, whereas forward signaling is not required for anterior commissure formation (Henkemeyer et al. 1996; Dravis et al. 2004).

We did not find developmental defects in ephrin-B $1^{6 F}$ mutant mice, indicating that PDZ-dependent reverse signaling may be the predominant reverse signaling pathway utilized by ephrin-B1. In vivo roles attributable to tyrosine phosphorylation-dependent reverse signaling have been identified for other B-type ephrins, however. Recent studies indicate that phosphorylation-dependent and PDZ-dependent reverse signaling by ephrin-B2 are involved in synaptic plasticity (Bouzioukh et al. 2007), and phosphorylation-dependent reverse signaling by ephrin-B3 through the Grb4 adaptor is critical for pruning of hippocampal mossy fiber axons during development (Xu and Henkemeyer 2009). It is possible, therefore, that phosphorylation-dependent reverse signaling by ephrinB1 may possess yet-unidentified importance in development or disease. Studies in cultured rat hippocampal neurons have suggested that phosphorylation-dependent reverse signaling by ephrin-B1 can regulate dendritic spine maturation in a mechanism involving Grb4 (Segura et al. 2007). It has been demonstrated recently that invasiveness of gastrointestinal carcinomas can be modulated by Ephrin-B1 phosphorylation-dependent reverse signaling (Tanaka et al. 2007). These results suggest the possibility that the ephrin- $B 1^{6 F}$ reverse signaling mice could possess resistance to metastasis of highly invasive gastric scirrhous carcinomas.
This is the first report analyzing point mutations that simultaneously abrogate both phosphorylation-dependent and PDZ-dependent reverse signaling for a B-type ephrin. Cooperativity between these signaling mechanisms is a possibility, since mice harboring a mutation removing the entire intracellular domain of ephrin-B2 display phenotypes not recapitulated by point mutations preventing PDZ-dependent or phosphorylation-dependent reverse signaling (Cowan et al. 2004; Dravis et al. 2004; Makinen et al. 2005). Our results indicate that cooperativity between the two signaling mechanisms is not a significant contributor to ephrin-B1 function during development.

PDZ-dependent reverse signaling by multiple B-type ephrins is clearly important for development and disease. The analogous $\Delta \mathrm{V}$ mutation in ephrin-B2 results in defective lymphatic remodeling (Makinen et al. 2005). The downstream signaling machinery responsible for propagating this signal in vivo has yet to be clearly elucidated; however, the localization of PDZ-RGS3 and Dvl2 were perturbed in ephrin- $B 2^{\Delta V}$ mutants, implicating both interactors as candidates (Makinen et al. 2005). Interestingly, PDZ-RGS3 has been shown previously to interact with ephrin-B1 in E16.5 cerebral cortices, and can modulate cerebellar granule cell migration driven by chemokine SDF-1 and its receptor CXCR4 in culture (Lu et al. 2001). In our preliminary studies, antibody staining revealed colocalization of ephrin-B1 and PDZRGS3 in cortical explant culture neurons, and PDZ-RGS3 was coexpressed with L1-CAM and ephrin-B1 on axons of the CC (Supplemental Fig. 5). PDZ-RGS3 is a particularly appealing candidate for mediating this reverse signal since CXCR4 is also expressed within cortical neurons, and SDF-1/CXCR4 signaling is capable of modulating axonal responsiveness to other known guidance cues (Chalasani et al. 2003; Stumm et al. 2003). PDZ-RGS3 expression and localization within axons of the CC appears to be maintained in ephrin- $B 1^{\Delta V}$ mutant brains (Supplemental Fig. 5E-J), although a detailed examination of subcellular colocalization will be required in future studies. Several other PDZ domain-containing proteins that can interact with ephrin-B1 have also been identified, and at least one other of these, protein interacting with C-kinase 1 (PICK1), is expressed within cortical axons in culture (data not shown). Identifying the PDZ domain-containing proteins that transduce Ephrin-B reverse signaling in specific in vivo contexts remains an important goal for future studies.

\section{Materials and methods}

Generation of Ephrin-B1 reverse signaling mutant mice

Targeting vectors for the generation of ephrin-B1 reverse signaling mutants included in $5^{\prime}$-to-3' order: a pGKDTAbpA-negative selection cassette, 1.5-kb EcoRI/BamHI 5' homology arm, FRTflanked pGKNEO-positive selection cassette, a floxed 2-kb BamHI/SpeI fragment containing the wild-type fifth axon, 2-kb BamHI/SpeI fragment containing a fifth exon containing one of three reverse signaling mutations, and a 4.2-kb SpeI/EcoRI 3' homology arm. Point mutations were made by successive rounds of 
site-directed mutagenesis using the Stratagene Quickchange protocol with the following primers and their reverse complement: ephrin- $B 1^{\Delta V}$ (primer 1, 5'-CATCTACTACAAGTGAAGGCCCA GCATGGC-3'); ephrin-B $1^{6 F}$ (primer 2, 5'-ACGGACTACAGAG AACAACTTCTGCCCCCACTTTGAGAAGGTGAG-3'), (primer 3, 5' -AGAAGGTGAGTGGGGACTTCGGGCATCCTGTCTTCA TCGTCCAGG-3'), (primer 4, 5'-GCTGGGCCTTCAAACCTT GAAGAAGATGTTCGCCGGGCTCTGAG-3'); ephrin- $B 1^{6 F \Delta V}$ was made by performing site-directed mutagenesis with primer pair 1 to modify the ephrin- $B 1^{6 F}$ mutant exon. For screening purposes, an Asp718 site was introduced into the 3' untranslated region (UTR) of all constructs by site-directed mutagenesis using the following primer and its reverse complement $5^{\prime}$-TCTG GGCTCCGTGGGGGTACCCTTTCTAGG-3'. Constructs were electroporated into AK7.1 Embryonic stem (ES) cells, and proper targeting was initially screened with a sense PCR primer located upstream of the start of the $5^{\prime}$ arm with sequence 5'-GTTCAGC CCCAACTACATGG-3' and a reverse primer recognizing sequences corresponding to the PGKNEObpA cassette with sequence 5'-CGGTGGGCTCTATGGCTTCTGAG-3', which amplified an $\sim 1.5$-kb band from targeted clones. PCR-positive ES cell clones were screened by Southern hybridization with $5^{\prime}$ and $3^{\prime}$ external genomic, and NEO internal probes to ensure single targeted insertion. The 5' probe was a HindIII/XhoI fragment of 539 base pairs (bp) in size, used to screen ES cell DNA digested with HindIII. Correctly targeted ES cell clones were injected for each construct, and resultant chimeras were bred with wild-type or ROSA $26^{\text {Flper }}$ mice in the $129 S 4$ congenic background to remove the FRT-flanked NEO cassette; this was confirmed by PCR with a forward primer corresponding to the $3^{\prime}$ end of the inserted PGKNEO cassette (5'-TCCTGCACGACGCGAGC TG- $3^{\prime}$ ), and a reverse primer complementary to the $5^{\prime}$ end of the fifth exon (5'-CGTAAGGGGATGATGATGTCGC-3'), which amplified a 465-bp product in the presence of Neo. Removal of the NEO cassette was confirmed by loss of this 465-bp product, as well as by the gain of a 641-bp product in a PCR with a forward primer in the fourth intron of efnb1 (5'-GAAGTCCC TGCTGCCTGCCTC-3'), and a reverse primer complementary to the $5^{\prime}$ end of the fifth exon (5'-CGTAAGGGGATGAT GATGTCGC-3'). To generate mice lacking ephrin-B1 reverse signaling, we crossed ephrinB1 $1^{10 \times 6 F /+}$, ephrinB1 $1^{\text {lox } \Delta V /+}$, and ephrinB1 ${ }^{10 x 6 F \Delta V /+}$ heterozygous females to Meox2-cre' mice (Tallquist et al. 2000), which results in epiblast-wide recombination and generation of ephrin- $B 1^{\Delta V}$, ephrin- $B 1^{6 F}$, and ephrin$B 1^{6 F \Delta V}$ mutant mice, respectively. The presence of the floxed wild-type fifth exon was detected by a forward primer in the $3^{\prime}$ end of the fifth exon of efnb1 (5'-ACCTCCACACTGCCTCC TGG-3') and a reverse primer corresponding to the $5^{\prime}$ end of the (mutant) fifth exon (5'-CGTAAGGGGATGATGATGTCGC-3') amplifying a product of $722 \mathrm{bp}$. Resulting mice were backcrossed within the $129 S 4$ genetic background to ensure germline recombination, and to breed out the Meox2-cre allele prior to analysis.

\section{Immunoprecipitation and Western blotting}

For immunoprecipitation, E17.5 brains were dissected in cold PBS, and homogenized by trituration in NP40 buffer (containing 20 $\mathrm{mM}$ Tris- $\mathrm{HCl}$ at $\mathrm{pH} 8,137 \mathrm{mM} \mathrm{NaCl}, 10 \%$ glycerol, $1 \%$ Ipegal [NP-40], 2 mM EDTA). Extracts were cleared by centrifugation for $15 \mathrm{~min}$ at $4^{\circ} \mathrm{C}$ and precleared for $1 \mathrm{~h}$ with protein $\mathrm{A} / \mathrm{G}$ beads. Immunoprecipitation was performed with $2 \mu \mathrm{g}$ of anti-ephrin-B1 (R\&D Systems), $1.25 \mu \mathrm{g}$ of anti-EphB2 (R\&D Systems) for $4 \mathrm{~h}$ at $4^{\circ} \mathrm{C}$, followed by incubation for $1 \mathrm{~h}$ with protein $\mathrm{A} / \mathrm{G}$ beads; washing and elution were performed according to standard protocols with NP40 buffer. Western blotting was performed according to standard protocols with antibodies recognizing EphB2 (R\&D
Systems), Ephrin-B1 (Santa Cruz Biotechnologies), phosphorylated tyrosine (Millipore-Upstate Biotechnologies), PDZ-RGS3 (Lu et al. 2001), and Pick1 (Santa Cruz Biotechnologies).

\section{Histology, skeletal analysis, and DiI tracing}

For histology, brains were dissected and fixed in Bouin's fixative, dehydrated through a graded series of ethanol, and embedded in paraffin. Sections were cut at $8 \mu \mathrm{M}$ and stained with hematoxylin and eosin. Skeletal preparations were performed as described (Martin et al. 1995). For DiI axon labeling, brains were dissected at E17.5 and fixed in 4\% PFA. A single crystal of DiI was placed in the dorsomedial cortex and allowed to diffuse for 1 mo. Horizontal vibratome sections of $50 \mu \mathrm{m}$ thickness were cut and stained with DAPI before mounting and imaging.

\section{Antibody staining and in situ hybridization}

For antibody staining, embryonic brains were removed and fixed in $4 \%$ PFA overnight at $4^{\circ} \mathrm{C}$. After dehydration in $25 \%$ sucrose, brains were embedded in OCT and cryosections were cut at a thickness of 12 or $14 \mu \mathrm{m}$. Immunofluorescence on sections was performed according to standard protocols with antibodies recognizing ephrin-B1 (1:15; R\&D Systems), EphB2 (1:20; R\&D Systems), EphB3 (1:20; R\&D Systems), L1-CAM (1:200; Chemicon), GFAP (1:15; Immunostar). In situ hybridization was performed as described elsewhere (Sciavolino et al. 1997).

\section{Cell culture and immunostaining of cells}

For membrane localization, primary mouse embryonic fibroblasts were isolated from E13.5 mouse palatal shelves to enrich for ephrin-B1-expressing cells by dissection and trypsinization, and were cultured in DMEM with 10\% FCS and passaged once before being cultured on glass coverslips. HEK293 cells transfected by the calcium phosphate method with the following expression vectors described previously: pcDNA3.1 ephrin-B1, pcDNA3.1 ephrin-B1 ${ }^{\Delta v}$ (Davy et al. 2004), and PDZ-RGS3-Myc (Lu et al. 2001). Coverslips with cells or explants were fixed in $4 \%$ PFA and washed with PBS, blocked in $5 \%$ donkey serum in PBS $+0.1 \%$ Triton, and incubated with primary antibody in PBS + $0.1 \%$ Triton for $1 \mathrm{~h}$. Coverslips were washed with PBS and incubated with fluorophore-conjugated secondary antibodies.

Cortical explant culture, growth cone collapse assay, and stripe assay

For cortical explants, E17.5 brains were dissected in ice-cold HEPES-buffered HBSS and cortices were removed. The dorsalmedial and cingulate cortex were then cut into $200-\mu \mathrm{m}$ squares and plated on coverslips coated with $1 \mathrm{mg} / \mathrm{mL}$ poly-D-lysine and $10 \mu \mathrm{g} / \mathrm{mL}$ Laminin (excluded for stripe assay), and cultured in neurobasal neuron growth medium with B27 supplement, pen/ strep, $500 \mu \mathrm{M}$ L-glutamine, and $500 \mu \mathrm{L}$ of 1 M HEPES (pH 7.4). Axons were allowed to grow for $2-3 \mathrm{~d}$ before analysis. Growth cone collapse assay was performed as described (Kapfhammer et al. 2007). After $2 \mathrm{~d}$ in culture, explants were treated with 10 $\mu \mathrm{g} / \mathrm{mL}$ unclustered EphB2-Fc, or Fc alone for $15 \mathrm{~min}$, and were then fixed. Cultures were stained with rhodamine phalloidin (Molecular Probes), before quantification. At least seven explants each from three independent wells were counted for the number of collapsed and uncollapsed axons for each treatment condition. A one-way analysis of variance (ANOVA) was calculated to compare growth cone collapse between no treatment, treatment with FC, and treatment with B2-Fc with an $\alpha$ level of 0.05 . The analysis was significant with $F(2,140)=40.6, P<0.001$. 
The stripe assay was performed as described in Knoll et al. (2007), with some modifications. To generate stripes, glass coverslips were coated with $1 \mathrm{mg} / \mathrm{mL}$ poly-D-lysine, washed, and coated with $2.4 \mu \mathrm{g} / \mathrm{mL}$ donkey anti-human antibody recognizing the Fc portion of human IgG. Coverslips were washed with PBS and silicon stripe matrices were applied and $30 \mu \mathrm{g} / \mathrm{mL}$ EphB2-Fc, or $30 \mu \mathrm{g} / \mathrm{mL} \mathrm{Fc}$ alone was injected into matrices and allowed to sit for $2.5 \mathrm{~h}$. Matrices were removed and carpets were washed with PBS, followed by several washes with HBSS, and addition of cortical explant media (same as above). Ten explants were placed in three rows on stripe carpets, and axon outgrowth was allowed to proceed for $3 \mathrm{~d}$. Coverslips were fixed in 4\% PFA with $10 \%$ sucrose and then stained with antibodies recognizing $\beta$-tubulin (Covance) to visualize axons, and an antibody recognizing EphB2 (R\&D Systems) in experimental, or an antibody recognizing human Fc (Jackson immunoresearch) in control, to visualize stripes. Explants displaying significant axonal outgrowth $(>10$ axons from an explant) and that were separated from adjacent explants were evaluated for response to stripes.

\section{Acknowledgments}

We thank Qiang Lu for kindly providing us with antibodies against PDZ-RGS3, and a PDZ-RGS3-Myc expression construct, and Deanna Benson for allowing us use of stripe assay matrices. We are grateful to Nancy Ann Oberheim, Ioana Carcea, Dan Felsenfeld, Sergi Simo, and our laboratory colleagues for helpful advice and discussions, and comments on the manuscript. Outstanding technical assistance was provided by Philip Corrin and Amelie Cornil. J.O.B. was supported by a Ruth L. Kirschstein NRSA Individual Fellowship from NIH/NIDCR F32 (DE17506). The work was supported by grants RO1HD24875 and R37HD25326 from the National Institute for Child Health and Human Development to P.S.

\section{References}

Adams RH, Wilkinson GA, Weiss C, Diella F, Gale NW, Deutsch U, Risau W, Klein R. 1999. Roles of ephrinB ligands and EphB receptors in cardiovascular development: Demarcation of arterial/venous domains, vascular morphogenesis, and sprouting angiogenesis. Genes \& Dev 13: 295-306.

Bagri A, Marin O, Plump AS, Mak J, Pleasure SJ, Rubenstein JL, Tessier-Lavigne M. 2002. Slit proteins prevent midline crossing and determine the dorsoventral position of major axonal pathways in the mammalian forebrain. Neuron 33: 233-248.

Birgbauer E, Cowan CA, Sretavan DW, Henkemeyer M. 2000. Kinase independent function of EphB receptors in retinal axon pathfinding to the optic disc from dorsal but not ventral retina. Development 127: 1231-1241.

Birgbauer E, Oster SF, Severin CG, Sretavan DW. 2001. Retinal axon growth cones respond to EphB extracellular domains as inhibitory axon guidance cues. Development 128: 3041-3048.

Blits-Huizinga CT, Nelersa CM, Malhotra A, Liebl DJ. 2004. Ephrins and their receptors: Binding versus biology. IUBMB Life 56: 257-265.

Bong YS, Park YH, Lee HS, Mood K, Ishimura A, Daar IO. 2004. Tyr-298 in ephrinB1 is critical for an interaction with the Grb4 adaptor protein. Biochem J 377: 499-507.

Bouzioukh F, Wilkinson GA, Adelmann G, Frotscher M, Stein V, Klein R. 2007. Tyrosine phosphorylation sites in ephrinB2 are required for hippocampal long-term potentiation but not long-term depression. J Neurosci 27: 11279-11288.

Bruckner K, Pasquale EB, Klein R. 1997. Tyrosine phosphorylation of transmembrane ligands for Eph receptors. Science 275: $1640-1643$.
Chalasani SH, Sabelko KA, Sunshine MJ, Littman DR, Raper JA. 2003. A chemokine, SDF-1, reduces the effectiveness of multiple axonal repellents and is required for normal axon pathfinding. J Neurosci 23: 1360-1371.

Chong LD, Park EK, Latimer E, Friesel R, Daar IO. 2000. Fibroblast growth factor receptor-mediated rescue of $\mathrm{x}$-ephrin B1-induced cell dissociation in Xenopus embryos. Mol Cell Biol 20: 724-734.

Compagni A, Logan M, Klein R, Adams RH. 2003. Control of skeletal patterning by ephrinB1-EphB interactions. Dev Cell 5: 217-230.

Cowan CA, Henkemeyer M. 2001. The SH2/SH3 adaptor Grb4 transduces B-ephrin reverse signals. Nature 413: 174179.

Cowan CA, Yokoyama N, Saxena A, Chumley MJ, Silvany RE, Baker LA, Srivastava D, Henkemeyer M. 2004. Ephrin-B2 reverse signaling is required for axon pathfinding and cardiac valve formation but not early vascular development. Dev Biol 271: 263-271.

Davy A, Soriano P. 2005. Ephrin signaling in vivo: Look both ways. Dev Dyn 232: 1-10.

Davy A, Aubin J, Soriano P. 2004. Ephrin-B1 forward and reverse signaling are required during mouse development. Genes \& Dev 18: 572-583.

Davy A, Bush JO, Soriano P. 2006. Inhibition of gap junction communication at ectopic Eph/ephrin boundaries underlies craniofrontonasal syndrome. PLoS Biol 4: e315. doi: 10.1371/ journal.pbio.0040315.

Dickson BJ. 2002. Molecular mechanisms of axon guidance. Science 298: 1959-1964.

Dravis C, Yokoyama N, Chumley MJ, Cowan CA, Silvany RE, Shay J, Baker LA, Henkemeyer M. 2004. Bidirectional signaling mediated by ephrin-B2 and EphB2 controls urorectal development. Dev Biol 271: 272-290.

Egea J, Klein R. 2007. Bidirectional Eph-ephrin signaling during axon guidance. Trends Cell Biol 17: 230-238.

Henkemeyer M, Orioli D, Henderson JT, Saxton TM, Roder J, Pawson T, Klein R. 1996. Nuk controls pathfinding of commissural axons in the mammalian central nervous system. Cell 86: 35-46.

Holland SJ, Gale NW, Mbamalu G, Yancopoulos GD, Henkemeyer M, Pawson T. 1996. Bidirectional signalling through the EPHfamily receptor Nuk and its transmembrane ligands. Nature 383: 722-725.

Hu Z, Yue X, Shi G, Yue Y, Crockett DP, Blair-Flynn J, Reuhl K, Tessarollo L, Zhou R. 2003. Corpus callosum deficiency in transgenic mice expressing a truncated ephrin-A receptor. $J$ Neurosci 23: 10963-10970.

Kalo MS, Yu HH, Pasquale EB. 2001. In vivo tyrosine phosphorylation sites of activated ephrin-B1 and ephB2 from neural tissue. J Biol Chem 276: 38940-38948.

Kapfhammer JP, Xu H, Raper JA. 2007. The detection and quantification of growth cone collapsing activities. Nat Protocols 2: 2005-2011.

Knoll B, Weinl C, Nordheim A, Bonhoeffer F. 2007. Stripe assay to examine axonal guidance and cell migration. Nat Protocols 2: 1216-1224.

Lee HS, Mood K, Battu G, Ji YJ, Singh A, Daar IO. 2009. Fibroblast growth factor receptor-induced phosphorylation of ephrinB1 modulates its interaction with Dishevelled. Mol Biol Cell 20: 124-133.

Lin D, Gish GD, Songyang Z, Pawson T. 1999. The carboxyl terminus of $\mathrm{B}$ class ephrins constitutes a PDZ domain binding motif. J Biol Chem 274: 3726-3733.

Lu Q, Sun EE, Klein RS, Flanagan JG. 2001. Ephrin-B reverse signaling is mediated by a novel PDZ-RGS protein and 
selectively inhibits $\mathrm{G}$ protein-coupled chemoattraction. Cell 105: 69-79.

Makinen T, Adams RH, Bailey J, Lu Q, Ziemiecki A, Alitalo K, Klein R, Wilkinson GA. 2005. PDZ interaction site in ephrinB2 is required for the remodeling of lymphatic vasculature. Genes \& Dev 19: 397-410.

Mann F, Miranda E, Weinl C, Harmer E, Holt CE. 2003. B-type Eph receptors and ephrins induce growth cone collapse through distinct intracellular pathways. I Neurobiol 57: 323-336.

Martin JF, Bradley A, Olson EN. 1995. The paired-like homeo box gene MHox is required for early events of skeletogenesis in multiple lineages. Genes \& Dev 9: 1237-1249.

Mendes SW, Henkemeyer M, Liebl DJ. 2006. Multiple Eph receptors and B-class ephrins regulate midline crossing of corpus callosum fibers in the developing mouse forebrain. $I$ Neurosci 26: 882-892.

Orioli D, Henkemeyer M, Lemke G, Klein R, Pawson T. 1996. Sek4 and Nuk receptors cooperate in guidance of commissural axons and in palate formation. EMBO $J$ 15: 6035-6049.

Palmer A, Zimmer M, Erdmann KS, Eulenburg V, Porthin A, Heumann R, Deutsch U, Klein R. 2002. EphrinB phosphorylation and reverse signaling: Regulation by Src kinases and PTP-BL phosphatase. Mol Cell 9: 725-737.

Paul LK, Brown WS, Adolphs R, Tyszka JM, Richards LJ, Mukherjee P, Sherr EH. 2007. Agenesis of the corpus callosum: Genetic, developmental and functional aspects of connectivity. Nat Rev Neurosci 8: 287-299.

Richards LJ. 2002. Surrounded by Slit-How forebrain commissural axons can be led astray. Neuron 33: 153-155.

Richards LJ, Plachez C, Ren T. 2004. Mechanisms regulating the development of the corpus callosum and its agenesis in mouse and human. Clin Genet 66: 276-289.

Risley M, Garrod D, Henkemeyer M, McLean W. 2008. EphB2 and EphB3 forward signalling are required for palate development. Mech Dev 126: 230-239.

Sciavolino PJ, Abrams EW, Yang L, Austenberg LP, Shen MM, Abate-Shen C. 1997. Tissue-specific expression of murine Nkx3.1 in the male urogenital system. Dev Dyn 209: 127138.

Segura I, Essmann CL, Weinges S, Acker-Palmer A. 2007. Grb4 and GIT1 transduce ephrinB reverse signals modulating spine morphogenesis and synapse formation. Nat Neurosci 10: $301-310$.

Shu T, Richards LJ. 2001. Cortical axon guidance by the glial wedge during the development of the corpus callosum. I Neurosci 21: 2749-2758.

Shu T, Puche AC, Richards LJ. 2003. Development of midline glial populations at the corticoseptal boundary. J Neurobiol 57: 81-94.

Smith KM, Ohkubo Y, Maragnoli ME, Rasin MR, Schwartz ML, Sestan N, Vaccarino FM. 2006. Midline radial glia translocation and corpus callosum formation require FGF signaling. Nat Neurosci 9: 787-797.

Stumm RK, Zhou C, Ara T, Lazarini F, Dubois-Dalcq M, Nagasawa T, Hollt V, Schulz S. 2003. CXCR4 regulates interneuron migration in the developing neocortex. I Neurosci 23: 5123-5130.

Su Z, Xu P, Ni F. 2004. Single phosphorylation of Tyr304 in the cytoplasmic tail of ephrin B2 confers high-affinity and bifunctional binding to both the SH2 domain of Grb4 and the PDZ domain of the PDZ-RGS3 protein. Eur J Biochem 271: 1725-1736.

Tallquist MD, Klinghoffer RA, Heuchel R, Mueting-Nelsen PF, Corrin PD, Heldin CH, Johnson RJ, Soriano P. 2000. Retention of PDGFR- $\beta$ function in mice in the absence of phosphatidylinositol 3'-kinase and phospholipase $\mathrm{C} \gamma$ signaling pathways. Genes \& Dev 14: 3179-3190.

Tanaka M, Kamata R, Takigahira M, Yanagihara K, Sakai R. 2007. Phosphorylation of ephrin-B1 regulates dissemination of gastric scirrhous carcinoma. Am J Pathol 171: 68-78.

Thelemann A, Petti F, Griffin G, Iwata K, Hunt T, Settinari T, Fenyo D, Gibson N, Haley JD. 2005. Phosphotyrosine signaling networks in epidermal growth factor receptor overexpressing squamous carcinoma cells. Mol Cell Proteomics 4: 356-376.

Torres R, Firestein BL, Dong H, Staudinger J, Olson EN, Huganir RL, Bredt DS, Gale NW, Yancopoulos GD. 1998. PDZ proteins bind, cluster, and synaptically colocalize with Eph receptors and their ephrin ligands. Neuron 21: 1453-1463.

Twigg SR, Kan R, Babbs C, Bochukova EG, Robertson SP, Wall SA, Morriss-Kay GM, Wilkie AO. 2004. Mutations of ephrinB1 (EFNB1), a marker of tissue boundary formation, cause craniofrontonasal syndrome. Proc Natl Acad Sci 101: 86528657.

Wahlsten D, Bishop KM, Ozaki HS. 2006. Recombinant inbreeding in mice reveals thresholds in embryonic corpus callosum development. Genes Brain Behav 5: 170-188.

Wieland I, Jakubiczka S, Muschke P, Cohen M, Thiele H, Gerlach KL, Adams RH, Wieacker P. 2004. Mutations of the ephrin-B1 gene cause craniofrontonasal syndrome. Am I Hum Genet 74: 1209-1215.

Wieland I, Reardon W, Jakubiczka S, Franco B, Kress W, VincentDelorme C, Thierry P, Edwards M, Konig R, Rusu C, et al. 2005. Twenty-six novel EFNB1 mutations in familial and sporadic craniofrontonasal syndrome (CFNS). Hum Mutat 26: 113-118.

$\mathrm{Xu}$ NJ, Henkemeyer M. 2009. Ephrin-B3 reverse signaling through Grb4 and cytoskeletal regulators mediates axon pruning. Nat Neurosci 12: 268-276.

Yokoyama N, Romero MI, Cowan CA, Galvan P, Helmbacher F, Charnay P, Parada LF, Henkemeyer M. 2001. Forward signaling mediated by ephrin-B3 prevents contralateral corticospinal axons from recrossing the spinal cord midline. Neuron 29: $85-97$. 


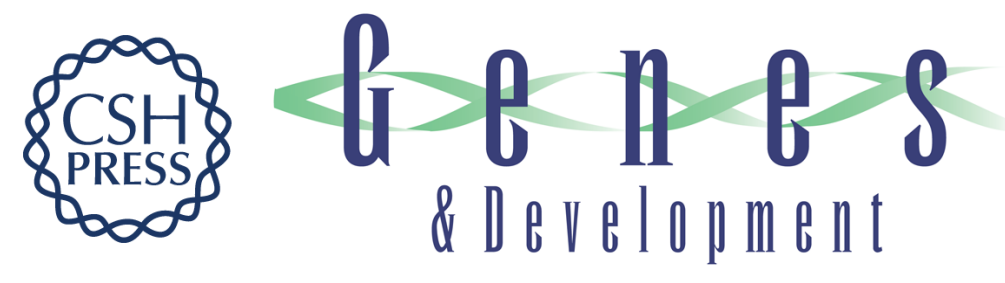

\title{
Ephrin-B1 regulates axon guidance by reverse signaling through a PDZ-dependent mechanism
}

\author{
Jeffrey O. Bush and Philippe Soriano
}

Genes Dev. 2009, 23: originally published online June 10, 2009

Access the most recent version at doi:10.1101/gad.1807209

\section{Supplemental http://genesdev.cshlp.org/content/suppl/2009/06/11/gad.1807209.DC1 Material}

References This article cites 55 articles, 21 of which can be accessed free at: http://genesdev.cshlp.org/content/23/13/1586.full.html\#ref-list-1

\section{License}

Email Alerting

Receive free email alerts when new articles cite this article - sign up in the box at the top Service

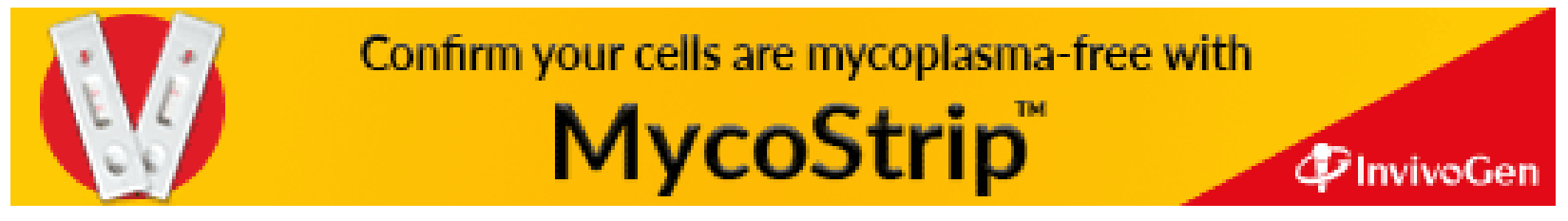

